\title{
The Effects of Linear Microphone Array Changes on Computed Sound Exposure Level Footprints
}

\author{
Arnold W. Mueller \\ NASA, Langley Research Center \\ Mark R. Wilson \\ Lockheed Martin Space Mission Systems and Services
}

\section{'ABSTRACT}

Airport land planning commissions often are faced with determining how much area around an airport is affected by the sound exposure levels (SELs) associated with helicopter operations. This paper presents a study of the effects changing the size and composition of a microphone array has on the computed SEL contour (ground footprint) areas used by such commissions. Descent flight acoustic data measured by a fifteen microphone array were reprocessed for five different combinations of microphones within this array. This resulted in data for six different arrays for which SEL contours were computed. The fifteen microphone array was defined as the "baseline" array since it contained the greatest amount of data. The computations used a newly developed technique, the Acoustic Re-propagation Technique (ART), which uses parts of the NASA noise prediction program ROTONET. After the areas of the SEL contours were calculated the differences between the areas were determined. The area differences for the six arrays are presented that show a five and a three microphone array (with spacing typical of that required by the FAA FAR Part 36 noise certification procedure) compare well with the fifteen microphone array.

All data were obtained from a database resulting from a joint project conducted by NASA and U.S. Army researchers at Langley and Ames Research Centers. A brief description of the joint project test design, microphone array set-up, and data reduction methodology associated with the database are discussed.

\section{INTRODUCTION}

Numerous research papers have addressed many issues in the helicopter noise community. One of these issues is the need to predict helicopter noise relative to the rotor blade dynamics resulting from helicopter flights. Most of

${ }^{1}$ Presented at the 1997 Sound and Vibration Conference of the Society of Automotive Engineers International, May 20-22, Traverse City, MI these papers compare predicted acoustic results obtained from analytical data to measured model data obtained from wind tunnels [1-5]. Another issue is that for four-bladed mediumweight helicopters, there are very few full scale flight measurements of far-field acoustics which may be used for comparisons with wind tunnel data [6] or which may be used in studies relative to the effects flight operations may have on acoustics. In the area of flight acoustics, there is the issue of how serious is it if any changes in the acoustics measurements technique occurs during the data acquisition stage (i.e. a malfunction of one or more acoustic data channels effectively causing an unplanned array configuration change). The effects of these changes on final results could only be evaluated if comparable data were obtained both before and after the changes. Finally, land planning commissions are often called upon to consider land uses around airports. Often noise considerations from helicopter operations are very important when deciding how the land area is to be used. However, the issue exists of how many microphones and what spacing should there be between sensors to obtain the needed sound exposure level (SEL) contours (ground footprints).

Because little or no information existed relative to the issues noted in the previous paragraph, a joint research project was conducted by personnel from NASA and the U.S. Army at Langley and Ames Research Centers to address some of them. The primary goal of the joint project was to establish a high quality full-scale flight noise database. This goal was achieved. In addition to far-field acoustic data which was measured by a fifteen microphone linear array, the database also contains time synchronized helicopter operations data, data associated with the physics and dynamics of the operation of the main rotor blade, and weather data. This database permits research personnel an opportunity to study current and future analysis and prediction techniques, and to compare full scale acoustic results to existing model data. The approach to establishing the database was to simultaneously measure the far-field acoustics, flight dynamics, numerous variables associated with the main rotor blade (including upper and lower surface pressures) of a UH-60A helicopter and the weather variables associated with the flight 
environment of the helicopter. These measurements were obtained as the helicopter flew standard flight profiles and maneuver profiles typical of those which occur during airport terminal area operations. All flights were conducted at the Naval Auxiliary Landing Facility, Crows Landing, CA., during November, 1993. References 7 through 9 discuss the details of the test set-up, test variables, data acquisition and reduction phases and the initial acoustics results obtained from the flight test.

The goal of this paper was to use data from the UH$60 \mathrm{~A}$ database to calculate and compare ground areas for computed SEL contours associated with six different combinations of microphones in a linear array. Decent flight acoustic data measured by the fifteen microphone array were reprocessed for five different combinations of microphones within this array. This produced data for six different arrays for which SEL ground contours were computed. The areas of the SEL contours were then to be compared to those obtained for the fifteen microphone array which for this paper was defined as the baseline array. If the comparisons were favorable it was thought reasonable to propose that acoustics data which may be used by land planning commissions could be collected with a minimum of resources and that significant cost savings should result if an array smaller than fifteen microphones (which is needed for detailed research purposes) were used to obtain the required flight noise data.

Parenthetically it is noted that it takes approximately four to six personnel three to four days to successfully survey fifteen microphone positions, deploy several thousand feet of instrumentation cables, and calibrate all microphone systems (from mic through to the tape recorder).

For research purposes, arrays of this size and larger are necessary to measure the detailed structure of the acoustic signals at ground stations. It was believed that for purposes other than research, smaller array sizes may be acceptable to use and still produce quality results.

In this paper, area results of SEL contour determinations for the five different microphone arrays are compared to a sixth array, defined as the baseline array, and presented in graphics format. The five other arrays consisted of seven, five and three microphones, with two different distributions of microphones each for the five and three microphone arrays. As part of the array selection process, it was noted that FAA guidelines for aircraft noise certification require data to be collected at three ground locations (centerline and \pm 150 meters perpendicular to the centerline). Since the UH-60A database contained data collected at microphone locations with spacing between each other comparable to these FAA dimensions this particular array setup was selected. The selection of the other four arrays was based on an engineering judgement of what was believed to be the most complete spatial sampling of the lower hemispherical sound field, the quantity of data associated with the arrays, and the available resources to obtain and study the results.

The focus of the SEL computations is on the Acoustic Re-propagation Technique (ART) presented in reference 9. The ART was developed using the acoustic data set collected from the fifteen ground microphone array used in the joint UH-60A flight test project. These data were used to estimate a lower hemispherical sound field that is used as an input into a part of the NASA noise prediction program ROTONET to propagate the acoustic energy to a grid of ground observers and generate contours of SELs.

A brief discussion of the aircraft, description of the instrumentation, type of measurements made, and the physical layout of the microphones used to acquire the far field flight noise along with a table of the several different aircraft descent operations follows.

\section{DATA INSTRUMENTATION AND ACQUISITION}

A highly instrumented UH-60A helicopter was flown for conditions representative of those which occur during airport terminal area operations. Figure 1 is a photograph of the aircraft, indicating two features associated with the test instrumentation onboard the aircraft. Close inspection of the figure shows a mylar sleeve placed over one of the four main rotor blades, which in the figure is located to the starboard of the aircraft. This permitted the calibration of the surface pressure transducers located on the blade, A more prominent feature noted in the photograph is the dome-like configuration setting on top of the rotor hub. This is the Rotating Data Acquisition System (RDAS) which collected data from the main rotor sensors, conditioned it, and then transmitted the data through a slip ring into recorders located in the cabin.

FLIGHT PATH TRACKING SYSTEM - A ground-based laser tracking system was used to provide aircraft flight track data during the acoustic data acquisition. Laser reflecting cubes were installed on each landing gear fairing. System accuracy was estimated to be less than or equal to \pm 3 feet.

WEATHER MEASUREMENT SYSTEM Weather variables of barometric pressure, dry and wet bulb temperatures, relative humidity, wind speed and direction, were measured as a function of altitude by instrumentation suspended beneath a tethered balloon. The balloon, which was located approximately 2500 feet to the side of the aircraft flight track, was permitted to ascend and descend from ground level to an altitude of 400 feet. Data acquisition began approximately 30 minutes before each helicopter flight and continued continuously throughout the time acoustic data were acquired. No acoustic data were acquired if wind speeds at any altitude from ground level to 400 feet were equal to or exceeded 10 knots for any sustained time period. 
ACOUSTIC MEASUREMENT SYSTEM - Two acoustic instrumentation vans were used for this project, each with nine digital microphone systems. These eighteen systems composed two different microphone arrays. The microphone systems consisted of $1 / 2$ inch diameter condenser microphones fitted with grid caps and covered by commercially available foam wind screens. Each microphone was placed on a ground board which was 42 inches square by $1 / 2$ inch thick sheet of PVC. The output of each microphone, used as the input to an analog-to-digital converter after signal conditioning, was digitized at a rate of 10,000 samples a second to permit a maximum frequency bandwidth of $5 \mathrm{kHz}$. Each data sample taken was initiated by a command sent from a central processing unit located in each instrumentation van. All nine digital microphone channels for each system were commanded to sample at the same time, insuring synchronization between channels.

The linearity, sensitivity, distortion, and noise floor of each microphone, and its signal conditioning and recording electronics were calibrated in the laboratory and documented to be linear to within $\pm 1 \mathrm{~dB}$ before it was placed in the field. The frequency range of calibration was $5 \mathrm{~Hz}$ to $10 \mathrm{kHz}$. A piston phone operating at $250 \mathrm{~Hz}, 124 \mathrm{~dB}$ sound pressure level (SPL), was used in the field for calibration at the beginning and end of each day. Also, at the beginning and conclusion of data acquisition for each flight test, ambient noise levels were recorded.

Acoustic arrays - Figure 2 presents a sketch of the lay-out of the eighteen microphones used for acoustic data acquisition during helicopter descent operations. The sketch shows the microphones were placed in the form of a linear arrangement taking the shape of a " $\mathrm{T}$ " and forming two arrays, one with fifteen mics and one with four mics. Figure 2 shows the largest array consisted of 15 microphones forming the top of a "T" and the smallest array of 4 microphones forming a short leg of the " $T$ ". The sketch shows the centerline reference microphone (right handed coordinate system with $x=0, y=0, z=0$ ) is common to both the short leg and the top of the "T" design. The aircraft flight track is along the $x$ axis. The microphone spacing distribution to each side of the reference microphone is symmetrical. However the unequal spacing of the 15 microphones lying along the $y$ axis (perpendicular to the flight track) was selected to provide approximate $10^{\circ}$ increments of angular spacing of measured directivity angle at a flyover altitude of 250 feet above the centerline reference microphone. The spacing of the three microphones in the short leg portion of the " $\mathrm{T}$ " is in equal 200 foot increments. Data used in this paper were those only obtained by the fifteen microphones distributed along the $y$ axis. The $Y$ co-ordinates of the microphones are presented in Table 1.
Table 1. Microphone identification and $Y$ coordinates.

\begin{tabular}{|l|l|l|l|l|l|}
\hline $\begin{array}{l}\text { Mic } \\
\#\end{array}$ & $\begin{array}{l}\text { Y co- } \\
\text { ordinate }\end{array}$ & $\begin{array}{l}\text { Mic } \\
\#\end{array}$ & $\begin{array}{l}\text { Y co- } \\
\text { ordinate }\end{array}$ & $\begin{array}{l}\text { Mic } \\
\#\end{array}$ & $\begin{array}{l}\text { Y co- } \\
\text { ordinate }\end{array}$ \\
\hline & -1417.8 & 6 & 1 & 11 & 144.3 \\
\hline 2 & -561.5 & 7 & -44.1 & 12 & 209.8 \\
\hline 3 & -320.0 & 8 & 0 & 13 & 320.0 \\
\hline 4 & -209.8 & 9 & 41.1 & 14 & 561.5 \\
\hline 5 & -144.3 & 10 & 91.0 & 15 & 1417.8 \\
\hline
\end{tabular}

Figures 3 through 8 present sketches of the microphone arrangements for the six arrays used to compute the SELs in this study. Note that each microphone arrangement has a uniqueness. Thus either the number of microphones varies or for those cases where the same number of microphones are used (Figs. 5-8), the spacings between them are different. The arrangement ID and the number of microphones in each arrangement are presented in Table 2.

Table 2. Array identification number and microphone arrangement

\begin{tabular}{|c|c|}
\hline Arrangement ID \# & Included microphone \#'s \\
\hline 15 (Fig. 3) & all 15 microphones \\
\hline 7 (Fig. 4) & $1,2,4,8,12,14,15$ \\
\hline 5-1 (Fig. 5) & $1,2,8,14,15$ \\
\hline $5-2$ (Fig. 6) & $2,5,8,11,14$ \\
\hline 3-1 (Fig. 7) & $1,8,15$ \\
\hline 3-2 (Fig. 8) & $2,8,14$ \\
\hline
\end{tabular}

Arrangement ID \# 3-2, Figure 8, most closely resembles the spacing setup for microphones used to certify flight noise data as required by the FAA FAR Part 36.

TEST CONDITIONS AND FLIGHT PATHS Acoustic data were obtained only during quiescent weather conditions. The first data flight of each test day began at dawn and continued until refueling was necessary or as long as the wind conditions remained below 10 knots. Flight time was generally limited to no longer than four hours on any one test day so that excessive pilot fatigue was avoided. Descent (approach) conditions flown during the joint test are tabulated in Table 3. 
Table 3. Number of data flights and test conditions for descent runs of UH-60A ( $x$ - test conditions for which data not obtained).

\begin{tabular}{|l|l|l|l|l|l|l|}
\hline & \multicolumn{6}{|c|}{ Descent angles $\gamma$ (degrees) } \\
\hline $\begin{array}{l}\text { Speed, } \\
\text { kts. }\end{array}$ & 3 & 6 & 7 & 8 & 9 & 12 \\
\cline { 2 - 8 } & \multicolumn{6}{|c|}{ Number of "runs" -...--- } \\
\hline 40 & 3 & 3 & $\mathrm{x}$ & $\mathrm{x}$ & 2 & 2 \\
\hline 60 & 3 & 1 & $\mathrm{x}$ & $\mathrm{x}$ & 1 & 2 \\
\hline 80 & 2 & 1 & 1 & $\mathrm{x}$ & 1 & 2 \\
\hline 100 & 1 & $\mathrm{x}$ & $\mathrm{x}$ & $\mathrm{x}$ & 1 & 3 \\
\hline 120 & $\mathrm{x}$ & $\mathrm{x}$ & $\mathrm{x}$ & $\mathrm{x}$ & $\mathrm{x}$ & 2 \\
\hline
\end{tabular}

The path for the descent flight conditions of Table 3 is sketched in Figure 9. During descent, the aircraft flight path was such that it approached perpendicular to the $y$ axis of Figure 2 (along which the 15 microphones were distributed) at a prescribed descent angle such that it would pass over the reference microphone at an altitude of 250 feet. The descent was maintained until the aircraft reached an altitude of 100 feet where it leveled out and prepared for the next run. This flight path was achieved by the pilot using a flight guidance display which was programmed in conjunction with the laser tracking. Data used in this paper were selected from the 3 degree descent $40 \mathrm{knot}, 6$ degree descent 80 knot, and 12 degree descent 100 knot conditions (respectively noted as low, moderate and high speeds).

\section{DATA REDUCTION AND RESULTS}

Details of the data reduction procedures which were used to obtain the weather and acoustic data may be found in reference 7 . A brief discussion of each of these data follows.

WEATHER DATA - Weather data (barometric pressure, wind speed and direction, dry and wet bulb temperature, and relative humidity) were used to calculate the sound speed profile for the helicopter flights for the time period associated with each set of acoustic runs selected for analysis. Throughout this time period, typically there was always less than a $2 \%$ sound speed change from the minimum to the maximum value for these data.

ACOUSTIC DATA - Frequency resolution - The acoustic data, which had been digitized at a sample rate of 10,000 points per second, were processed in successive 4096 point blocks using a fast Fourier transform (FFT). This produced narrowband acoustic spectra with a frequency resolution of $2.44 \mathrm{~Hz}$, generated every 0.4096 seconds of reception time at each microphone.
Run selection - When more than one run was available for analysis, a statistical analysis technique using the concept of multivariate analysis was selected to evaluate each data run. This technique permitted the calculation of the generalized variance associated with a large number of helicopter state variables. For this selection process, variables chosen were the speed, pitch, yaw, and roll of the aircraft during the time acoustic data were acquired. The run selected was that with the lowest variance. It was reasoned that the run with the lowest generalized variance would be the most "stable" and thus produce the most reasonable RDAS data to relate to the acoustic data. For the cases where there was more than one run, the variances ranged between $1.5 \mathrm{E}-3$ to 1.6 $\mathrm{E} 4$. In the multiple-run cases, individual runs selected for analysis were those with variances less than or equal to

4.3 E-3.

\section{ACOUSTIC RE-PROPAGATION TECHNIQUE}

- Since the descent flight conditions may be considered as "steady state" for the selected runs [7], it is assumed the acoustics associated with the helicopter operations are therefore not significantly changing. Figure 10 shows the steps taken in one stage of the two stage Acoustic Repropagation Technique, ART. This stage transforms the measured ground plane acoustic data into flight hemispherical sound fields. Figure 11 shows that in the other stage of ART, the sound fields and measured weather and flight dynamics data are used in parts of the NASA ROTONET noise prediction program.

For purposes of graphic simplicity, Figure 10 is sketched for an aircraft in level flight. However, the steps noted in the figure are directly applicable to descent flight as well as level flight. By using aircraft range tracking which has been calibrated relative to the reference microphone of the array [7], Figure 10 shows in step 1 that the acoustic directivity of the aircraft can be effectively sampled at the array (Fig. 2) as the aircraft systematically flies over it. This is accomplished since the recording time of the flight acoustic pressures at the array was synchronized with the flight time. Step 2 of Figure 10 shows that the directivity angles and their associated range vectors are next calculated and in step 3 these range vectors are translated back to a single point which will result in a surface which defines the ground coordinates. Steps 1 through 3 may be thought of as analogous to the methodology used in a wind tunnel to obtain acoustic directivity of a model. The model remains in one spot and a linear array of microphones perpendicular to the air flow is moved at a constant slow speed from ahead of the model towards it, then under it, and finally behind it. The acoustic directivity of the model is then determined by removing any tunnel environmental effects, along with Doppler speed, and inverse square law effects. In the case of full scale flight the acoustic directivity data must be adjusted for atmospheric absorption, ground reflection, and Doppler effects associated with helicopter speed. Once these effects are removed, step 4 
of Figure 10 may be accomplished. Step 4 requires the selection of a radius of a hemisphere and then computes the range vectors and their respective acoustic pressures associated with the measured directivity angles determined in step 2. These data are then used to estimate a lower hemispherical sound field which is normalized to the selected radius.

Figure 11 is a sketch depicting the Acoustic Repropagation Technique (ART). The sketch shows some of the modules of the NASA helicopter noise prediction program ROTONET and the hemispherical sound field determination discussed in the previous paragraph. As noted earlier, part of the ART consists of using the database measured weather and flight track data as input into the atmospheric and flight dynamics module parts of ROTONET. These modules, noted as dashed boxes, typically receive analytically determined inputs. The ROTONET atmospheric absorption module computes the effects the weather data (regardless of whether analytically modeled or measured) has on the acoustic pressures found in the noise source module of ROTONET. The geometry module computes the geometric relations between the noise source locations throughout the flight and ground observer locations associated with the noise source. Previous to the development of the flight hemispherical sound field determination stage of ART, the sound field used as input to the ROTONET noise source module, also noted as a dashed box, had always been analytically determined. By using the ART determination of the flight hemispherical sound field in the noise source module and then repropagating it to a grid of "receivers" at the ground, SEL contours or ground footprints may be generated. A more complete discussion of ART is found in reference 9.

SOUND EXPOSURE LEVELS - For each of the six microphone arrangements presented in Table 2 , sound exposure level contours were computed using ART and measured data obtained during a 6 degree $80 \mathrm{knot}$ (moderate) speed descent flyover, typical for a landing approach for this helicopter. The SEL contour differences between the baseline (15 mic) arrangement and the other five arrangements were then computed and are presented in Figure 12.

In addition to the 6 degree moderate speed descent flyover case, difference SEL ground contours were computed for the extreme descent cases of a 3 degree low speed (40 knots) descent flyover and a 12 degree high speed (100 knots) descent flyover. These cases permit a study of the effect microphone quantity and their relative positions have on the computed SEL ground contours (relative to the baseline 15 microphone case) for the extremes of the tested flight conditions. For this portion of the study, only two microphone configurations, $5-2$ and $3-2$ (Figs. $6 \& 8$ ), were considered along with the baseline 15 microphone case. This is because a study of figure 12 appears to suggest that among the considerations of mic arrangements 5-1, 5-2, 3-1, and 3-2, arrangement 5-2 and 3-2 have the smallest differences. Figure 12 shows that relative to all the microphone configurations considered, the 7 microphone arrangement appears to have the lowest differences between it and the baseline. This arrangement was not considered for this portion of the study relative to the extremes. This is because it was not believed to represent a significant reduction in deployment effort relative to the 5 or 3 microphone arrangement. Since microphone configuration 3-2 closely represents the FAA certification requirement, this permits a comparison of the effects this microphone arrangement has on the SEL contour relative to the baseline 15 microphone arrangement. Difference SEL ground footprints for the 3 degree low-speed descent and the 12 degree high-speed descent flyovers are presented in figures 13 and 14 respectively.

\section{RESULTS AND DISCUSSION}

A visual inspection of the results presented in Figure 12 for the 6 degree moderate speed descent flyover case suggests as the numbers of microphones decrease from 7 to 5 to 3 , the differences in the SEL ground contours relative to the 15 microphone case increase.

A study of the results for the extreme cases presented in Figures 13 and 14, shows that microphone arrangement 5 2 has the smallest differences of the two configurations, 5-2 and 3-2. This suggests arrangement 5-2 presents an SEL ground contour which more closely represents the 15 microphone baseline contour.

Observations of these results presented in Figures 12 , 13 , and 14 are not easily seen. In order to provide a better means of comparison between particular microphone arrangement results other than by visually observing the similarities between differences in SEL contours, footprint areas for selected contour magnitudes of levels were calculated. For the purposes of computing this footprint area six "closed-loop" contour magnitudes or levels were considered. The areas for the six footprint levels (A, B, C, D, $E$, and F) for the 6 degree, moderate speed descent flyover case are listed in table 4 . It is noted that level $A$ is greater than level B, B is greater than level C, C is greater than level $D, D$ is greater than $E$, and $E$ is greater than $F$. The magnitudes of the levels $A$ through $F$ are not presented because of security classification issues relative to the UH- 60 helicopter. By defining the 15 microphone baseline case to cover $100 \%$ of a particular footprint area, the relative percent area coverage to the baseline area may be determined for each microphone arrangement. This percent is also presented in Table 4. The data in Table 4 are presented graphically in Figures 15 and 16. Attention is called to the fact that the inverse of the areas presented in Table 4 are presented graphically in Figure 15. This is because the area associated with the contour of SEL of magnitude A (the highest level) 
covers the smallest area. The small areas of some of these higher magnitude levels (i.e A \& B) are difficult to visualize on a graphic where area sizes associated with the lower magnitudes ( $E$ and $F$ ) are many times larger. Thus a graph of inverse areas highlights the higher SEL magnitude contours and provides a clearer graphic for comparison purposes.

The data in Table 4 and Figures 15 and 16 show that as the level decreases in magnitude (i.e. going from $A$ to $B$ through to $F$ ) for any single microphone arrangement the inverse of the area decreases which corresponds to area increases. This is expected since acoustic energy levels dissipate over distance, and thus over area, unless focal zones or "hot spots" occur as a result of significant wind speed or temperature gradients, which did not occur during data acquisition. Another observation from Figures 15 and 16 is that areas generally decrease in size (shown as an increase in the inverse area graphic) as the number of microphones used in the source calculation are decreased. It is interesting to note that between the two arrangements for each of the five and three microphone arrangements, layout 2 of each provides an approximation which more closely represents the baseline area. The reason for this is that layout 2 includes a more evenly distributed collection of microphones over the angles through which the acoustic energy is propagated. Finally, the areas associated for the 5-2 arrangement are between 75 and 88 percent of the areas for the baseline arrangement as compared to those for the 5-1 arrangement of 48 to 80 percent; the 3-2 arrangement of 45 to 75 percent; and the 3-1 arrangement of 19 to 46 percent.

Based on the results seen in examining the 6 degree, moderate speed descent flyover case, arrangements 5-2 and 32 were chosen to be used in the remaining calculations. Table 5 presents the area and percent coverage results for the 12 degree, high-speed descent flyover case. These numbers are presented graphically in Figures 17 - 18. The inverse of the contour areas is again used as a method of comparing relative areas and is presented in Figure 17. Due the fact that no closed-loop contours resulted from the calculations for the 3 degree low speed case, no ground footprint area values are available for this descent flyover case.

Figure 17 shows that as the number of microphones changes from 15 in the array to the arrangement of 5-2 and then to the 3-2 arrangement, the 3-2 arrangement appears to more closely represent the inverse area results of the 15 microphone arrangement. This is perhaps better seen in the results displayed in Figure 18, which shows that for six different SEL amplitudes A through F, between 37 and 66 percent of the baseline ground footprint area can be recovered by using a five microphone arrangement as shown in figure 6 (i.e. microphone arrangement 5-2). This implies, however that these results which estimate the area that would be covered by six different SEL's measured by a fifteen microphone array has an error of -63 to -34 percent. If a 3-2 microphone arrangement comparable to the FAA setup (i.e. Figure 8) is used, the area recovered as related to a fifteen microphone baseline arrangement is between 70 percent and 126 percent, or an error of -30 percent to +26 percent. Thus the 3-2 microphone array more closely approximates the fifteen microphone array results than does the 5-2 microphone array set-up

Based on the results shown in figures 12 through 18 , it is believed that if a five microphone array with spacing between the microphones as noted in Figure 6 is used to measure descent flyover noise for three, six and twelve degrees at slow, moderate and high speeds, the resulting SEL data would well represent that which would be obtained from a 15 microphone array with the spacing between microphones as noted in Table 1. Furthermore the number of people and equipment needed to set up such a 5-2 array is significantly less than for a 15 or 7 microphone array (at least half as many people and half as much time). The number of personnel and time required to set up a 5-2 array is not that much more than that required for a 3-2 microphone array. Because of this, if limited resources are available, it appears reasonable that a 5 2 microphone array would be the best choice to measure SEL community noise levels for a wide range of helicopter descent conditions. If, because of significantly limited resources, only three microphones could be set up for the data acquisition of such a noise test, the selection of spacing between microphones which approximated that recommended by the FAA (Fig. 8) in its noise certification requirements may be advisable. Such a selection appears to produce SEL ground contour areas comparable to a fifteen microphone array, with some computed areas larger and some areas smaller than the areas computed for the fifteen microphone array.

\section{CONCLUSION}

Several papers discussing the research results obtained from a joint helicopter flight research project conducted by NASA and U.S. Army personnel have been produced. As part of the ongoing research associated with this database, a two stage technique termed Acoustic Repropagation Technique or ART, was developed. One stage of ART uses measured weather, flight dynamics and acoustic pressures to determine a flight hemispherical sound field. The other stage uses this flight hemispherical sound field, along with the measured weather and flight dynamics data as input to parts of the NASA helicopter noise prediction program ROTONET. Through re-propagation of this sound field to the ground plane, sound exposure level contours (a community noise metric) were obtained. ART gives land planning commissions a new tool to study the acoustic effects of helicopter operations in a community.

Differences in ground areas associated with SEL contours obtained from ART were studied for a range of 
helicopter descent angles and speeds. The results suggest that for limited resources, five microphones, in lieu of fifteen as needed to measure detailed flight acoustics for research projects, determine a reasonable approximation of the SEL ground footprint. Additionally, it was shown that if there were significant limits on resources, three microphones with a spacing representative of the FAA FAR PART 36 certification set up produces a SEL footprint which appears to be a reasonable representation of that determined by a fifteen microphone array.

Future research may be to implement the ART and SEL ground contour area computations used in this paper to examine more descent cases and level and ascent flyover cases in the UH-60A database to determine if similar trends as noted in this paper exist.

\section{REFERENCES}

1. Brentner, Kenneth S.; Marcolini, Michael A.; Burley, Casey L.; Sensitivity Of Acoustic Predictions To Variation Of Input Parameters: American Helicopter Society Technical Specialists Meeting, Rotorcraft Acoustics and Fluid Dynamics, October 15-16, 1991.

2. Marcolini, Michael A.; Martin, Ruth M.; Lorber, Peter F.; Egolf, T. Alan; Prediction Of BVI Noise Patterns And Correlation With Wake Interaction Locations, American Helicopter Society 48th Annual Forum, Washington, D.C., June 3-5, 1992.

3. Visintainer, J.A.; Burley, C.L.; Marcolini, M.A.; and Liu, S.R; Acoustic Predictions Using Measured Pressures From A Model Rotor In The DNW, American Helicopter Society 47th Annual Forum, Phoenix, AZ, May 6-9, 1991.

4. Liu, Sandy R.; Marcolini, Michael A.; The Acoustic Results Of A United Technologies Scale Model Helicopter Rotor Tested At DNW, American Helicopter Society 46th Annual Forum, Washington D.C., May 1990.

5. Burley, Casey L.; Martin, Ruth M.; Tip-Path-Plane Angle Effects On Rotor Blade-Vortex Interaction Noise Levels And Directivity, American Helicopter Society 44th Annual Forum, Washington D.C., June 1988.

6. Yamauchi, Gloria K.; Signor, David B.; Watts, Michael E.; Hernandez, Francisco J.; LeMasurier, Philip; Flight

Measurements Of Blade-Vortex Interaction Noise Including Comparisons With Full-Scale Wind Tunnel Data, American Helicopter Society 49th Annual Forum, St. Louis, Missouri, May 19-21, 1993.
7. Mueller, A.W., Conner, D.A., Rutledge, C.K., and Wilson; M.R.; Full Scale Flight Acoustic Results for the UH-60A Airloads Aircraft, Presented at American Helicopter Society Vertical Lift Aircraft Design Conference. San Francisco, CA, Jan 1995

.8. Rutledge, Charles K.; Mueller, Arnold W.; Wilson, Mark R.; A Study Of The Variability Difference Between Model Scale Wind Tunnel And Full Scale Flight Test Airloads Data, American Helicopter Society Vertical Lift Aircraft Design Conference, San Francisco, CA January 18-20, 1995.

9. Wilson, Mark R.; Mueller, Arnold W.; Rutledge, Charles K.; A New Technique For Estimating Ground Footprint Acoustics Using Measured Sound Fields, American Helicopter Society Vertical Lift Aircraft Design Conference, San Francisco, CA January 18-20, 1995.

\section{Biography}

Mr. Mueller has worked in acoustics research for more than 30 years at NASA, Langley Research Center. In the last 10 years he has conducted full scale flight acoustic tests on many different military and civil helicopters. He has produced more than 40 publications and presentations relative to helicopter long range noise propagation, acoustic detection, noise characteristics of maneuvers, noise within helicopters and noise reduction associated with flight track modification. 
Table 4. SEL ground contour areas (sq. $\mathrm{km}$ ) for six levels of magnitude A - F, differences and percents of baseline values for a 6 degree moderate speed descent flyover (magnitude $A>B>C>D>E>$ magnitude $F$ ).

Table 4. (a) SEL magnitudes A and B

\begin{tabular}{|c|c|c|c|c|c|c|}
\hline $\begin{array}{c}\text { Microphone } \\
\text { Arrangement }\end{array}$ & \multicolumn{7}{|c|}{ SEL Contour Level Area, Difference re. Baseline and } \\
& $\begin{array}{c}\text { Percent of Baseline Value } \\
\text { level A }\end{array}$ & $\begin{array}{c}\text { Delta } \\
\left(\mathrm{Km}^{2}\right)\end{array}$ & $\%$ & $\begin{array}{c}\text { area }\left(\mathrm{Km}^{2}\right) \\
\text { level B }\end{array}$ & $\begin{array}{c}\text { Delta } \\
\left(\mathrm{Km}^{2}\right)\end{array}$ & $\%$ \\
\hline 15 & 0.059 & 0.000 & 100 & 0.237 & 0.000 & 100 \\
\hline 7 & 0.061 & 0.002 & 103 & 0.216 & -0.021 & 91 \\
\hline $5-1$ & 0.047 & -0.012 & 80 & 0.119 & -0.118 & 50 \\
\hline $5-2$ & 0.050 & -0.009 & 85 & 0.178 & -0.059 & 75 \\
\hline $3-1$ & 0.027 & -0.033 & 46 & 0.049 & -0.188 & 21 \\
\hline $3-2$ & 0.044 & -0.016 & 75 & 0.132 & -0.105 & 56 \\
\hline
\end{tabular}

Table 4 continued. (b) SEL magnitudes $C$ and D

\begin{tabular}{|c|c|c|c|c|c|c|}
\hline $\begin{array}{c}\text { Microphone } \\
\text { Arrangement }\end{array}$ & \multicolumn{7}{|c|}{ SEL Contour Level Area, Difference re. Baseline and } \\
\hline & $\begin{array}{c}\text { area }\left(\mathrm{Km}^{2}\right) \\
\text { level C }\end{array}$ & $\begin{array}{c}\text { Delta } \\
\left(\mathrm{Km}^{2}\right)\end{array}$ & $\%$ & $\begin{array}{c}\text { area }\left(\mathrm{Km}^{2}\right) \\
\text { level D }\end{array}$ & $\begin{array}{c}\text { Delta } \\
\left(\mathrm{Km}^{2}\right)\end{array}$ & $\%$ \\
\hline 15 & 0.547 & 0.000 & 100 & 1.023 & 0.000 & 100 \\
\hline 7 & 0.478 & -0.069 & 87 & 0.872 & -0.151 & 85 \\
\hline $5-1$ & 0.262 & -0.285 & 48 & 0.702 & -0.321 & 69 \\
\hline $5-2$ & 0.435 & -0.112 & 80 & 0.902 & -0.121 & 88 \\
\hline $3-1$ & 0.104 & -0.443 & 19 & 0.400 & -0.623 & 39 \\
\hline $3-2$ & 0.246 & -0.301 & 45 & 0.647 & -0.376 & 63 \\
\hline
\end{tabular}

Table 4 concluded. (c) SEL magnitudes $E$ and $F$

\begin{tabular}{|c|c|c|c|c|c|c|}
\hline $\begin{array}{c}\text { Microphone } \\
\text { Arrangement }\end{array}$ & \multicolumn{7}{|c|}{ SEL Contour Level Area, Difference re. Baseline and } \\
\hline & $\begin{array}{c}\text { area }\left(\mathrm{Km}^{2}\right) \\
\text { level E }\end{array}$ & $\begin{array}{c}\text { Delta } \\
\left(\mathrm{Km}^{2}\right)\end{array}$ & $\%$ & $\begin{array}{c}\text { area }\left(\mathrm{Km}^{2}\right) \\
\text { level F }\end{array}$ & $\begin{array}{c}\text { Delta } \\
\left(\mathrm{Km}^{2}\right)\end{array}$ & $\%$ \\
\hline 15 & 2.322 & 0.000 & 100 & 4.243 & 0.000 & 100 \\
\hline 7 & 1.883 & -0.349 & 84 & 3.665 & -0.578 & 86 \\
\hline $5-1$ & 1.381 & -0.851 & 62 & 2.903 & -1.340 & 68 \\
\hline $5-2$ & 1.818 & -0.414 & 81 & 3.536 & -0.707 & 83 \\
\hline $3-1$ & 0.860 & -1.372 & 39 & 1.713 & -2.530 & 40 \\
\hline $3-2$ & 1.443 & -0.789 & 65 & 2.745 & -1.498 & 65 \\
\hline
\end{tabular}

Table 5. SEL ground contour areas (sq. $\mathrm{km}$ ) for six levels of magnitude $A-F$, differences and percents of baseline values for a 12 degree high speed descent flyover (magnitude $A>B>C>D>E>$ magnitude $F$ ).

Table 5. (a) SEL magnitudes A and B

\begin{tabular}{|c|c|c|c|c|c|c|}
\hline $\begin{array}{c}\text { Microphone } \\
\text { Arrangement }\end{array}$ & \multicolumn{7}{|c|}{ SEL Contour Level Area, Difference re. Baseline and } \\
& $\begin{array}{c}\text { Percent of Baseline Value } \\
\left.\text { area (Km }{ }^{2}\right) \\
\text { level A }\end{array}$ & $\begin{array}{c}\text { Delta } \\
\left(\mathrm{Km}^{2}\right)\end{array}$ & $\%$ & $\begin{array}{c}\text { area }\left(\mathrm{Km}^{2}\right) \\
\text { level B }\end{array}$ & $\begin{array}{c}\text { Delta } \\
\left(\mathrm{Km}^{2}\right)\end{array}$ & $\%$ \\
\hline 15 & 0.142 & 0.000 & 100 & 0.239 & 0.000 & 100 \\
\hline $5-2$ & 0.052 & -0.090 & 37 & 0.157 & -0.082 & 66 \\
\hline $3-2$ & 0.099 & -0.052 & 70 & 0.300 & 0.061 & 126 \\
\hline
\end{tabular}


Table 5 continued. (b) SEL magnitudes C and D

\begin{tabular}{|c|c|c|c|c|c|c|}
\hline \multirow[t]{2}{*}{$\begin{array}{l}\text { Microphone } \\
\text { Arrangement }\end{array}$} & \multicolumn{6}{|c|}{$\begin{array}{c}\text { SEL Contour Level Area, Difference re. Baseline and } \\
\text { Percent of Baseline Value }\end{array}$} \\
\hline & $\begin{array}{l}\text { area }\left(\mathrm{Km}^{2}\right) \\
\text { level } \mathrm{C}\end{array}$ & $\begin{array}{r}\text { Delta } \\
\left(\mathrm{Km}^{2}\right)\end{array}$ & $\%$ & $\begin{array}{l}\text { area }\left(\mathrm{Km}^{2}\right) \\
\text { level } \mathrm{D}\end{array}$ & $\begin{array}{l}\text { Delta } \\
\left(\mathrm{Km}^{2}\right)\end{array}$ & $\%$ \\
\hline 15 & 0.455 & 0.000 & 100 & 0.825 & 0.000 & 100 \\
\hline $5-2$ & 0.298 & -0.157 & 65 & 0.533 & -0.292 & 65 \\
\hline $3-2$ & 0.523 & 0.068 & 115 & 0.968 & 0.143 & 117 \\
\hline
\end{tabular}

Table 5 concluded. (c) SEL magnitudes $E$ and $F$

\begin{tabular}{|c|c|c|c|c|c|c|}
\hline $\begin{array}{c}\text { Microphone } \\
\text { Arrangement }\end{array}$ & \multicolumn{6}{|c|}{ SEL Contour Level Area, Difference re. Baseline and } \\
& \multicolumn{7}{|c|}{$\begin{array}{c}\text { Percent of Baseline Value } \\
\text { level E }\left(\mathrm{Km}^{2}\right)\end{array}$} & $\begin{array}{c}\text { Delta } \\
\left(\mathrm{Km}^{2}\right)\end{array}$ & $\%$ & $\begin{array}{c}\text { area }\left(\mathrm{Km}^{2}\right) \\
\text { level F }\end{array}$ & $\begin{array}{c}\text { Delta } \\
\left(\mathrm{Km}^{2}\right)\end{array}$ & $\%$ \\
\hline 15 & 2.042 & 0.000 & 100 & 3.734 & 0.000 & 100 \\
\hline $5-2$ & 1.129 & -0.913 & 55 & 2.410 & -1.324 & 65 \\
\hline $3-2$ & 1.732 & -0.310 & 85 & 3.501 & -0.233 & 94 \\
\hline
\end{tabular}




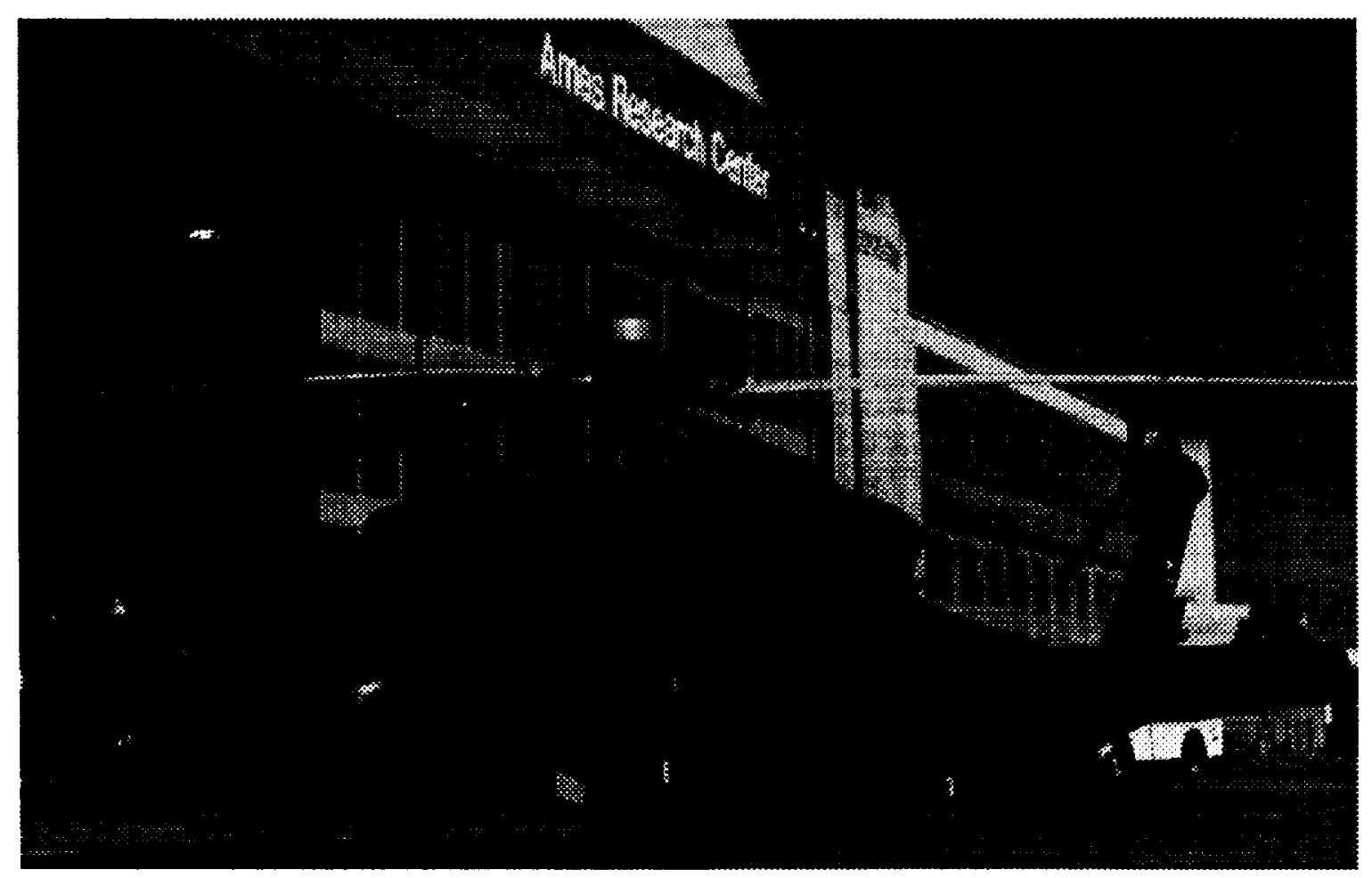

Flgure 1. UH-60A with Instrumented rotor blades

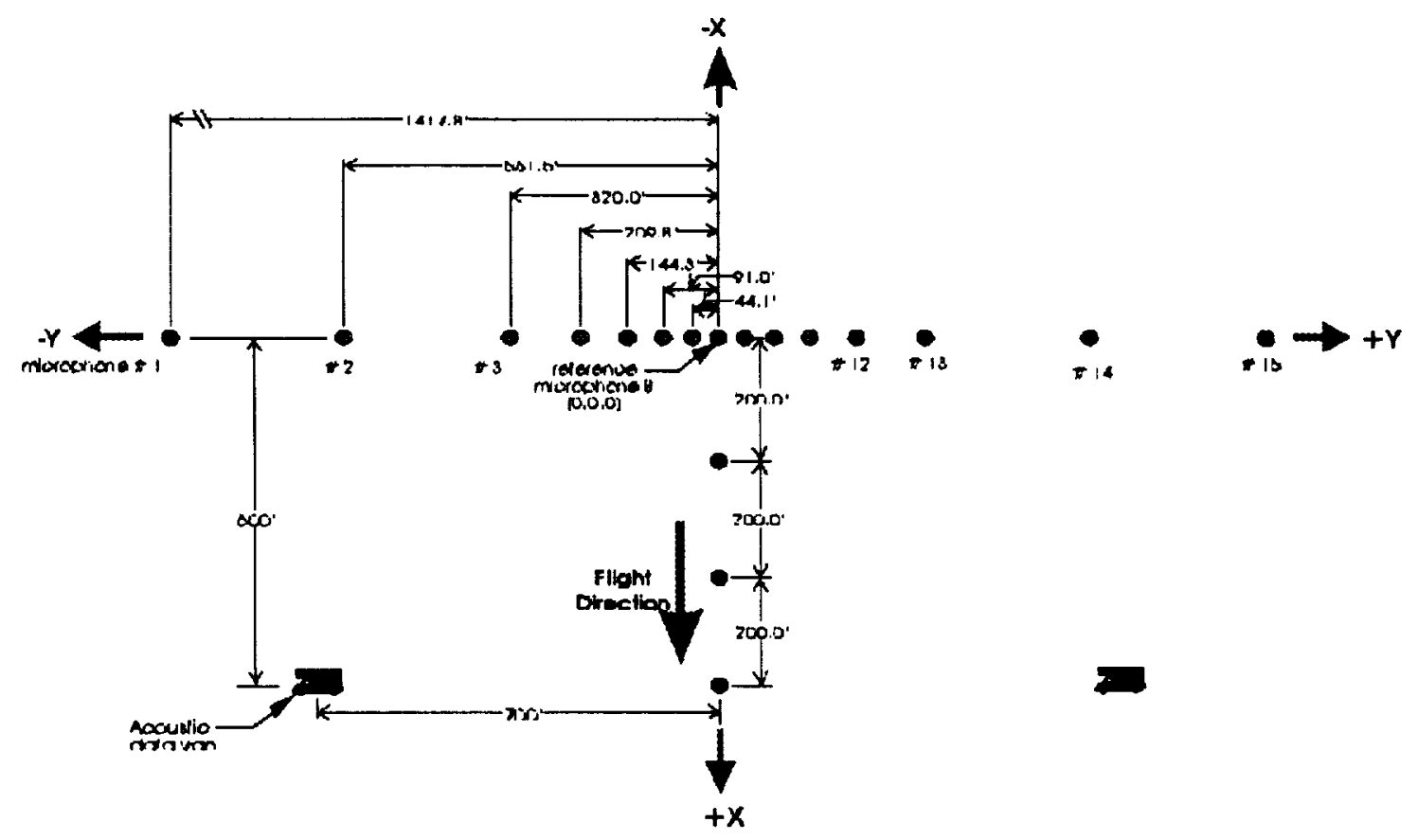

Figure 2. UH-60A acoustic tests microphone array. 


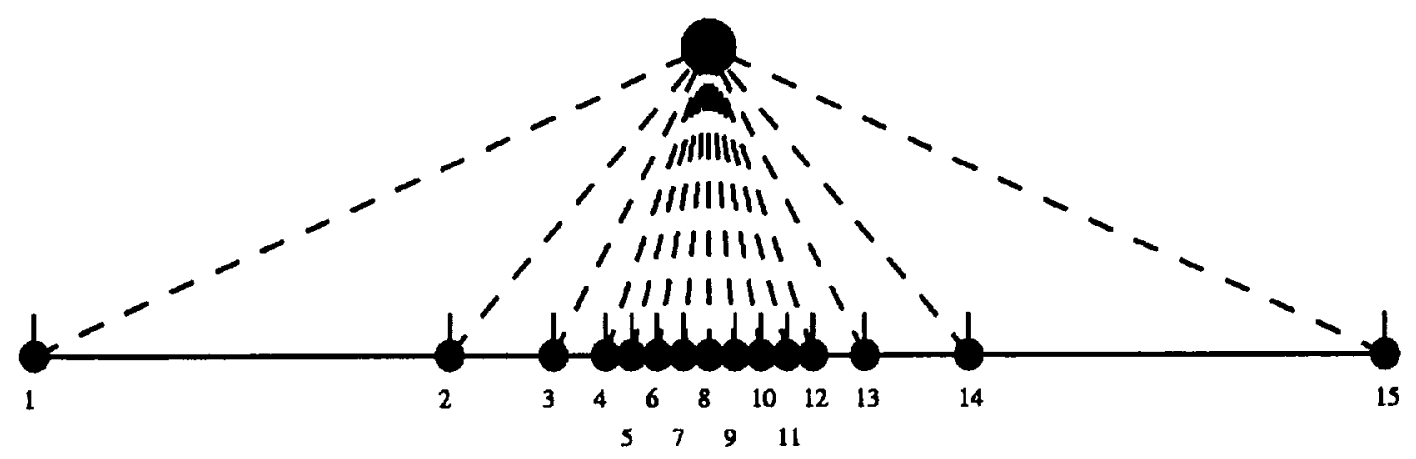

Figure 3. Microphone arrangement 15 baseline.

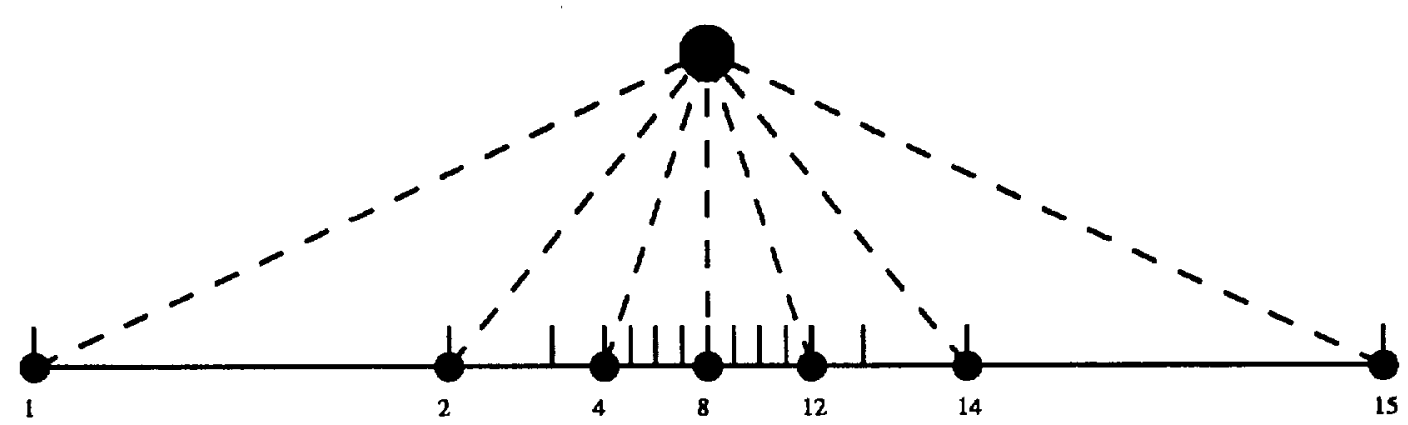

Figure 4. Microphone arrangement ?.

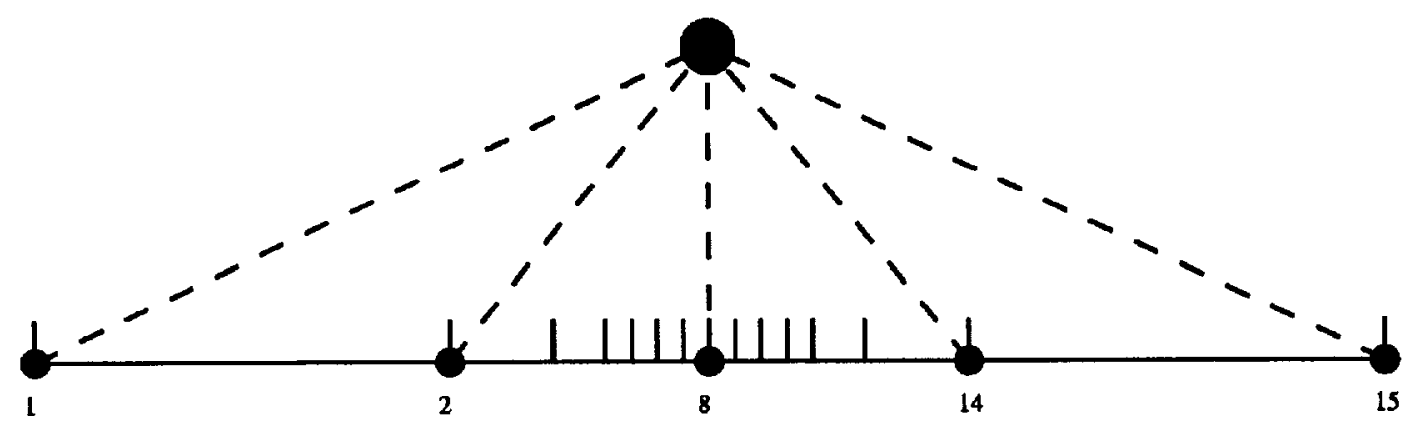

Figure 5. Microphone arrangement 5-1. 


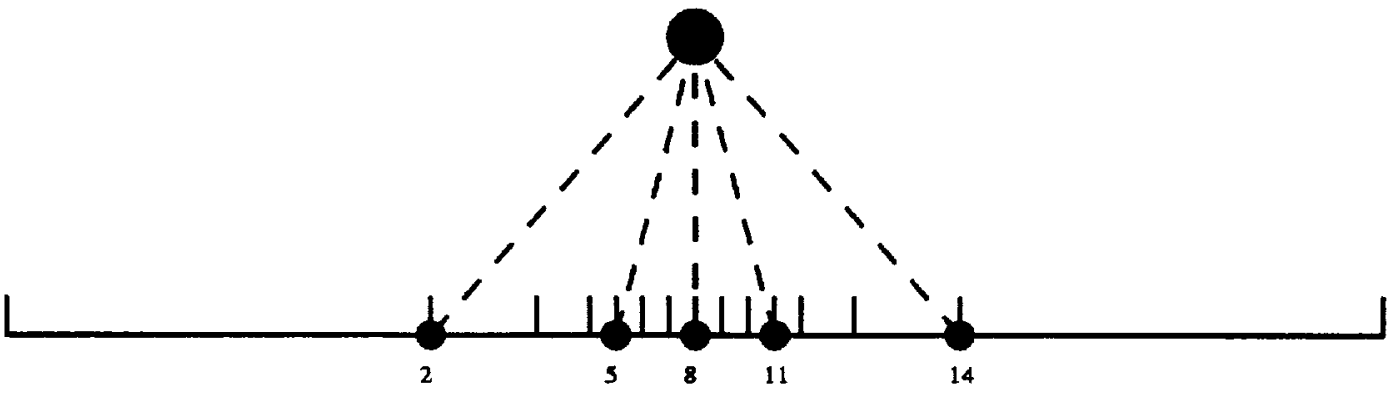

Figure 6. Microphone arrangement 5-2.

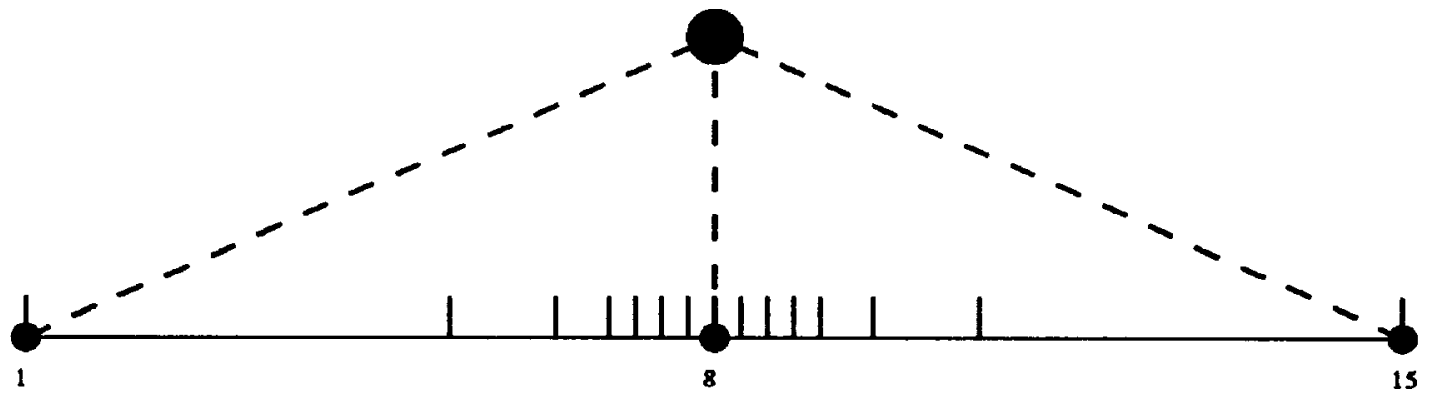

Figure 7. Microphone arrangement 3-1.

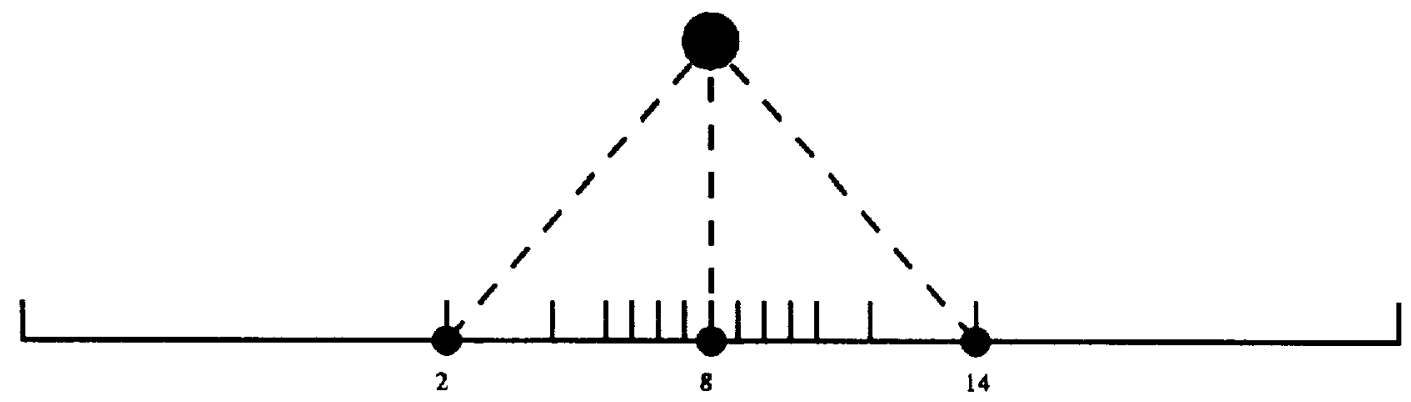

Flgure 8. Microphono arrangement 3-2, FAA suggented. 
Deacent Angle, $\gamma,=3^{\circ}, 6^{\circ}, 7^{\circ}, 8^{\circ}, 9^{\circ}, 12^{\circ}$

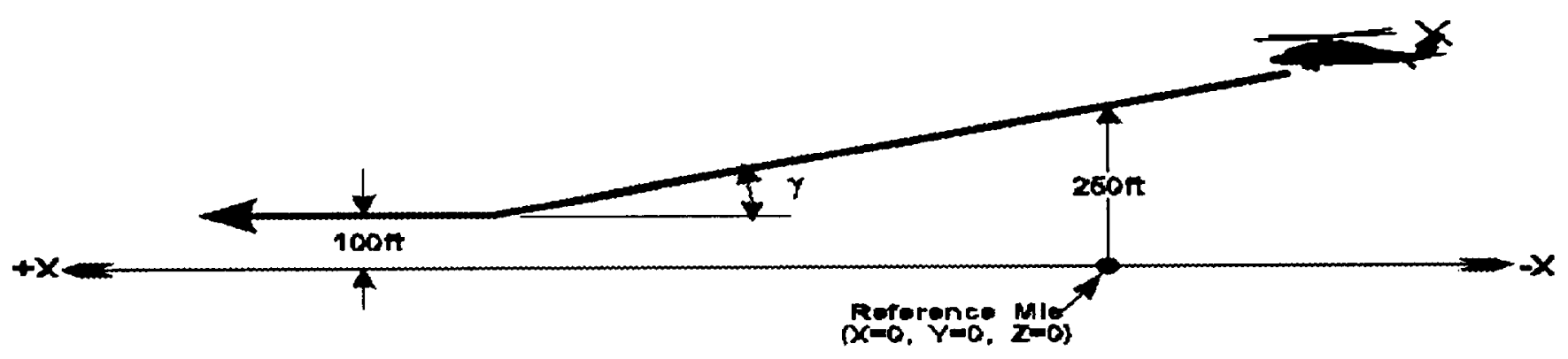

Figure 9. Flight profile for descent (approach) conditions.
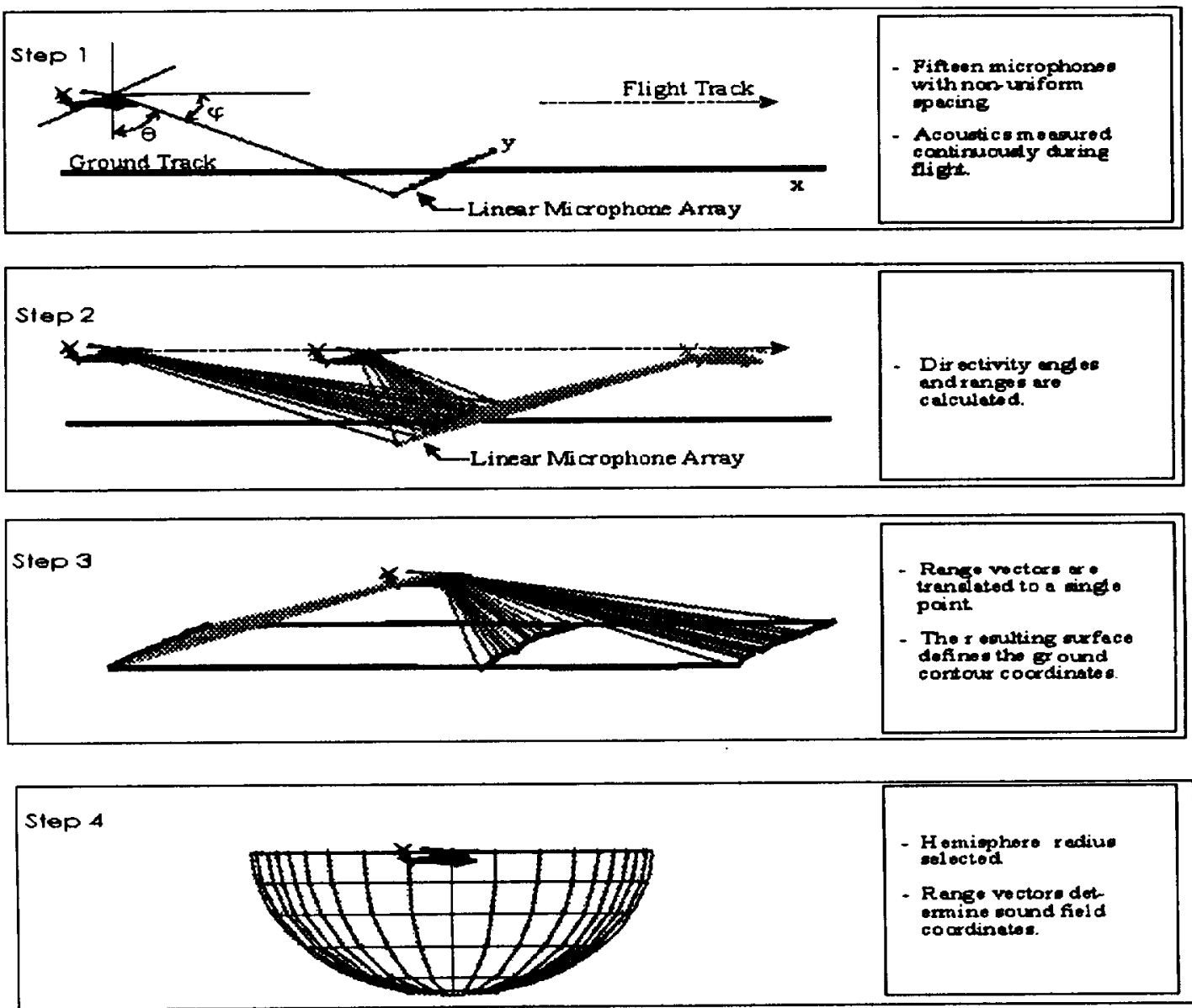

Figure 10. Hemispherical sound field determination. 
Atmosphere Module
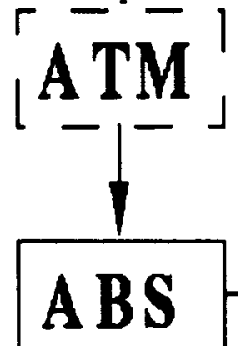

Atmospheric Absorption Module

Flight Dynamics Module

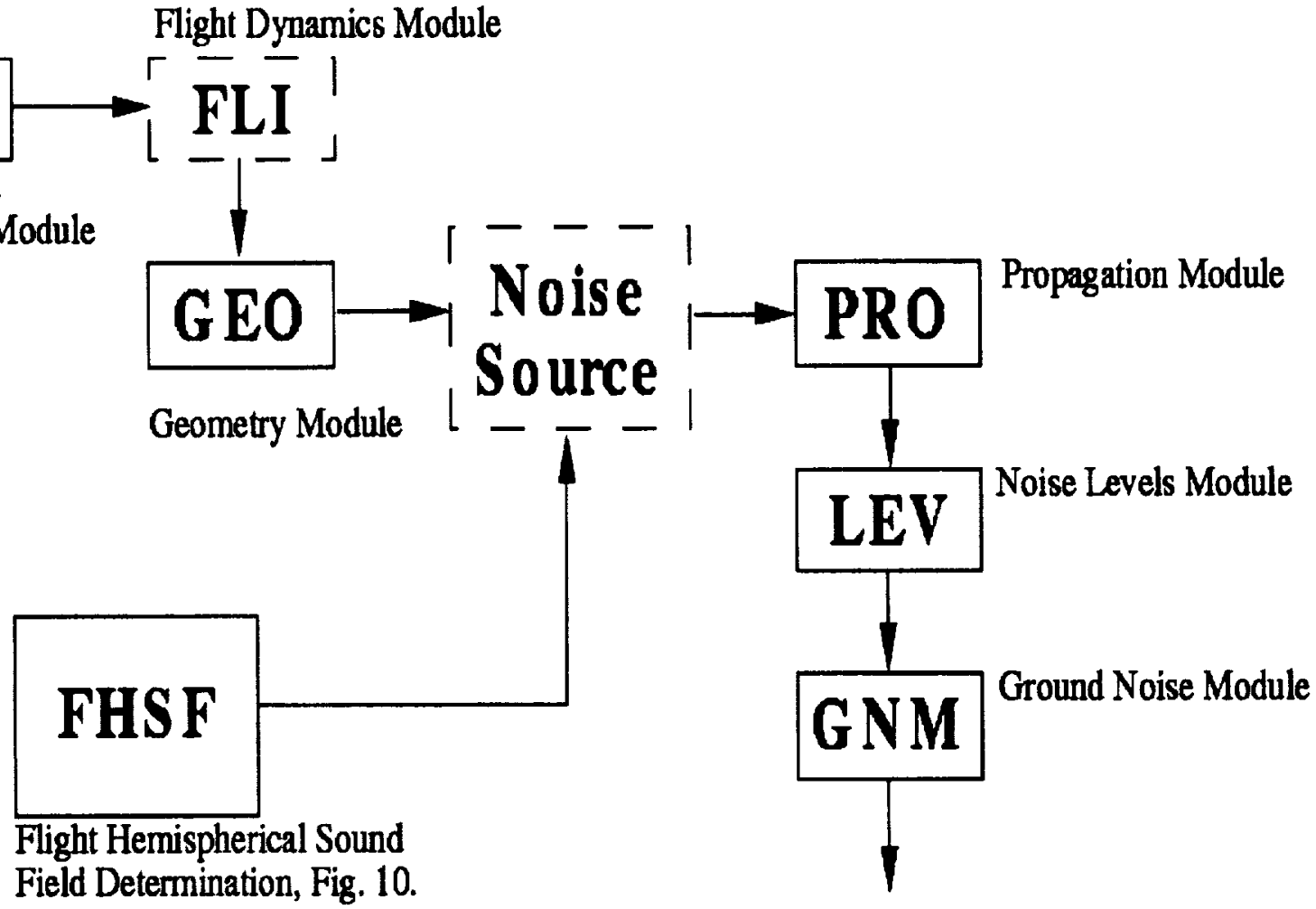

SEL Ground

Contour

Figure 11. Acoustic Re-propagation Technique. 


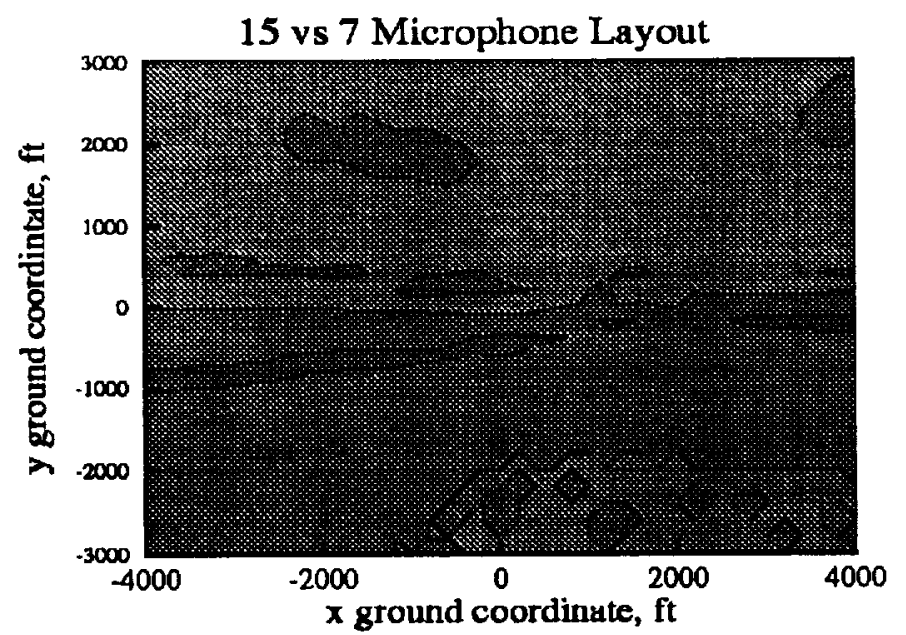

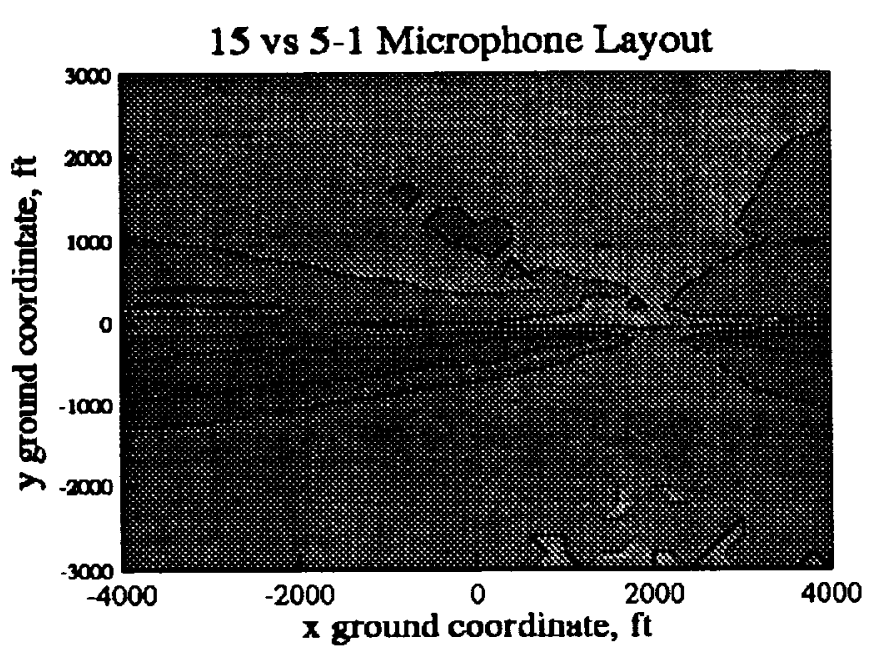

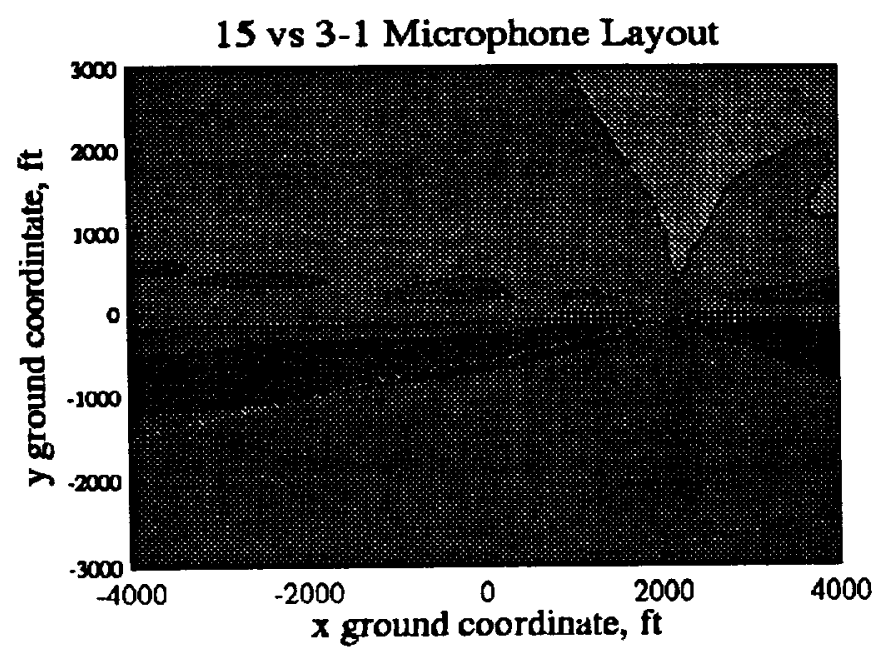

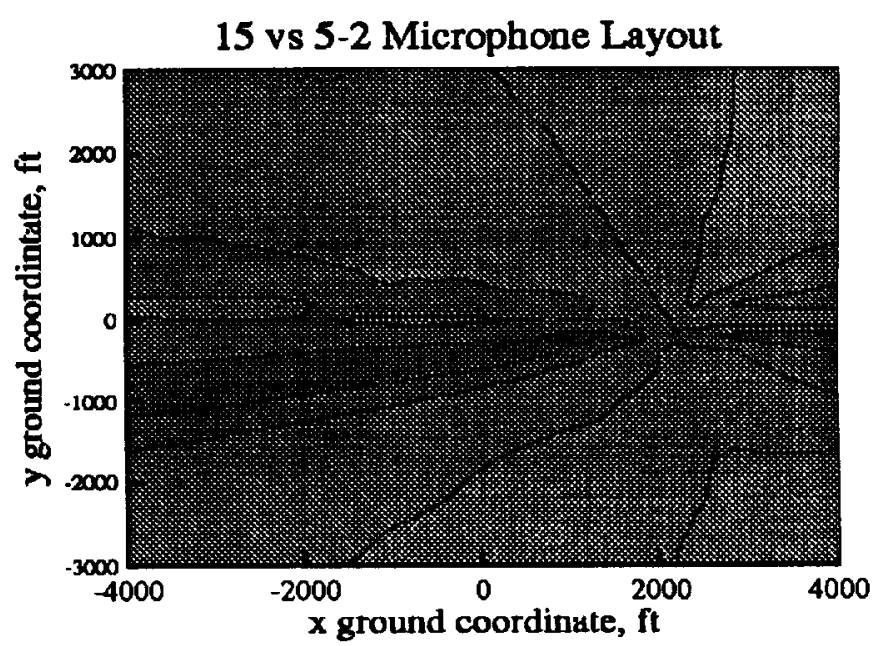

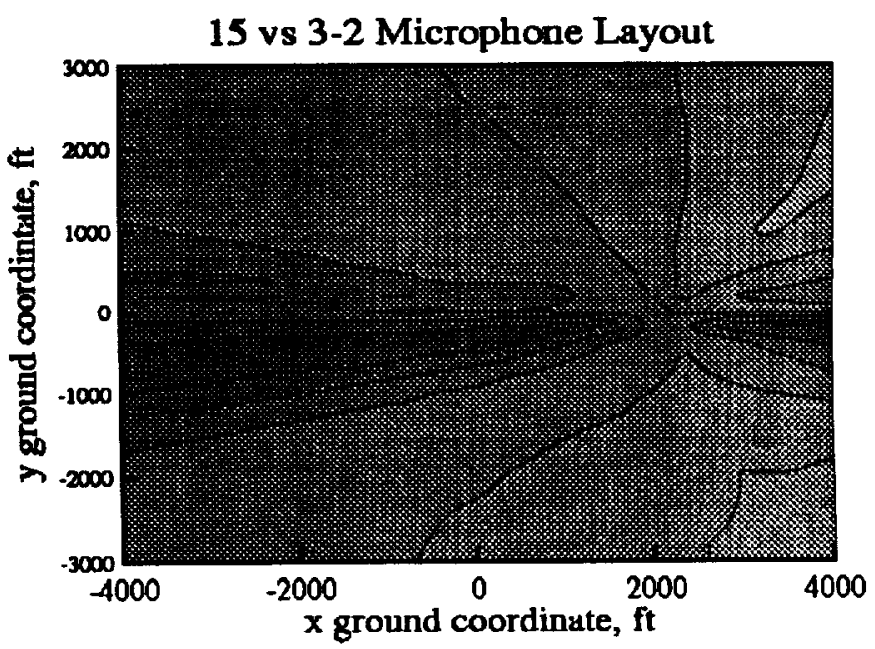

Figure 12. SEL difference contours for mid-speed, $6^{\circ}$ descent flyover. 
15 vs $5-2$ Microphone Layout

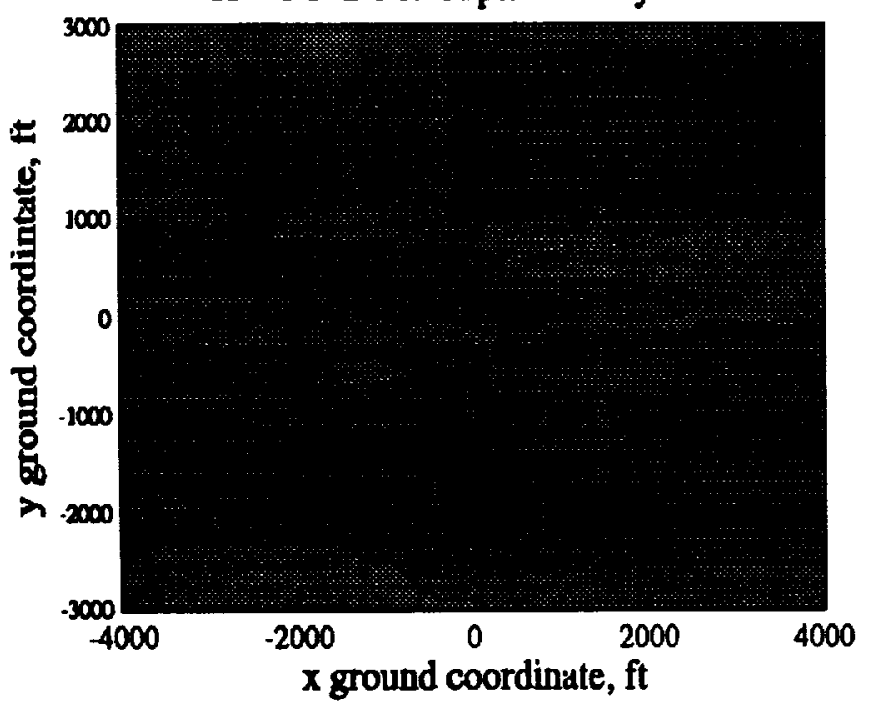

15 vs 3-2 Microphone Layout

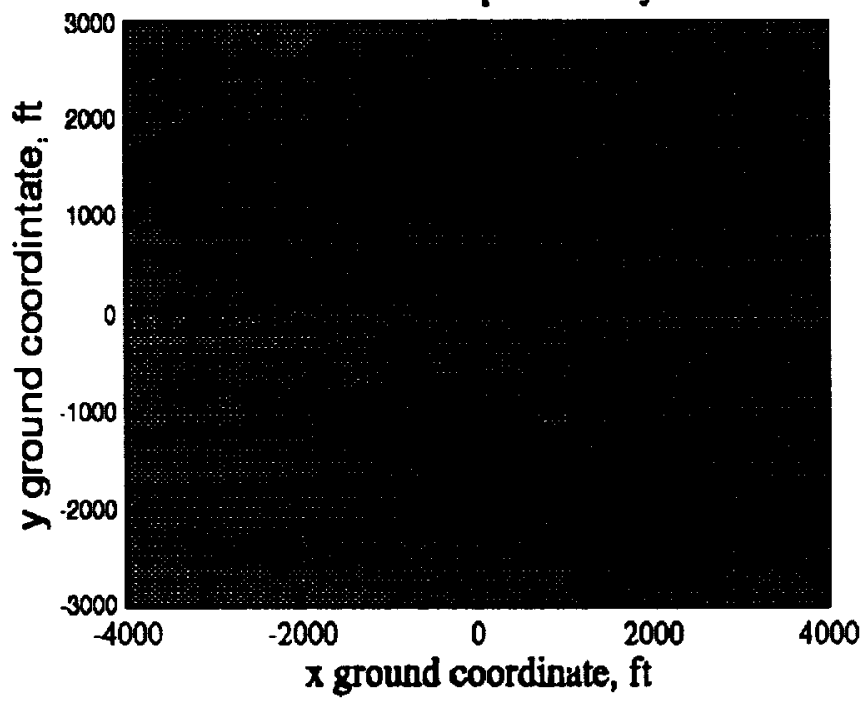

Figure 13. SEL difference contours for low-speed, $3^{\circ}$ descent flyover.
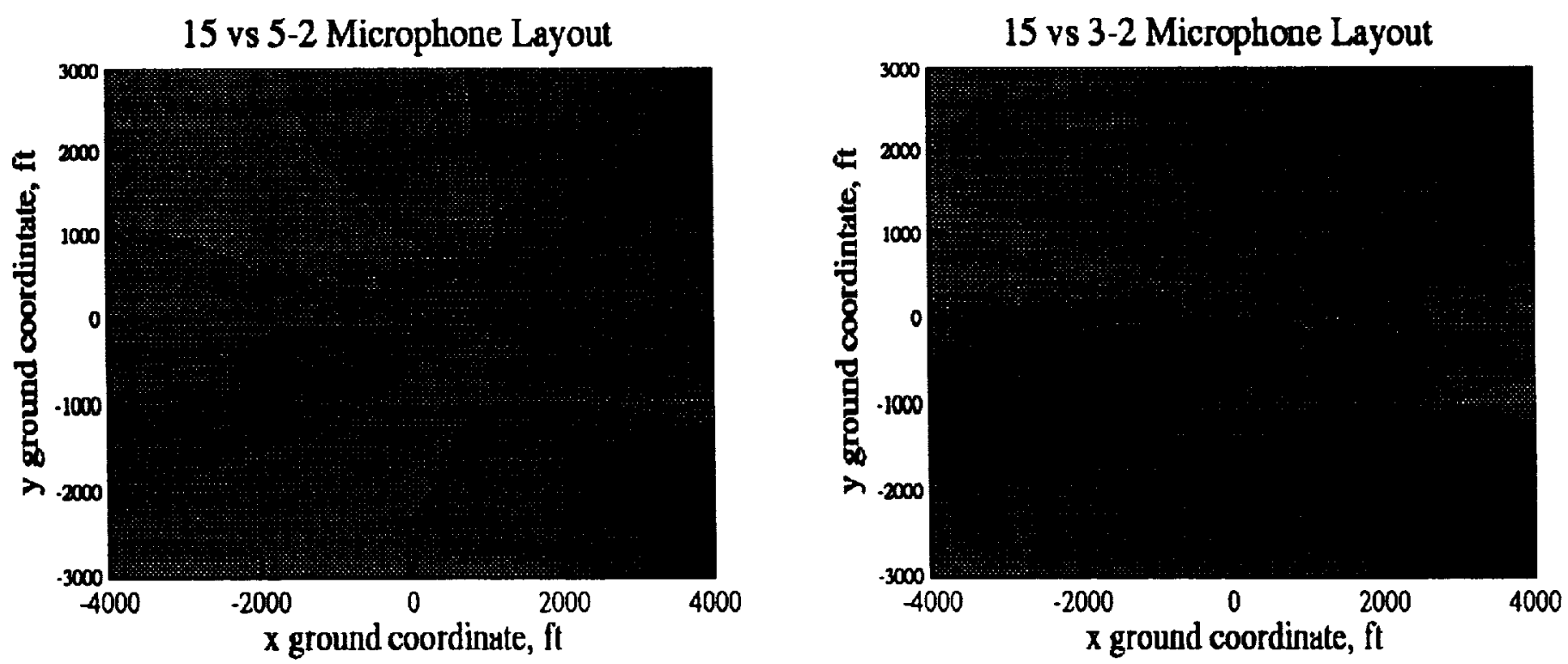

Figure 14. SEL difference contours for high-speed, $12^{\circ}$ descent flyover. 


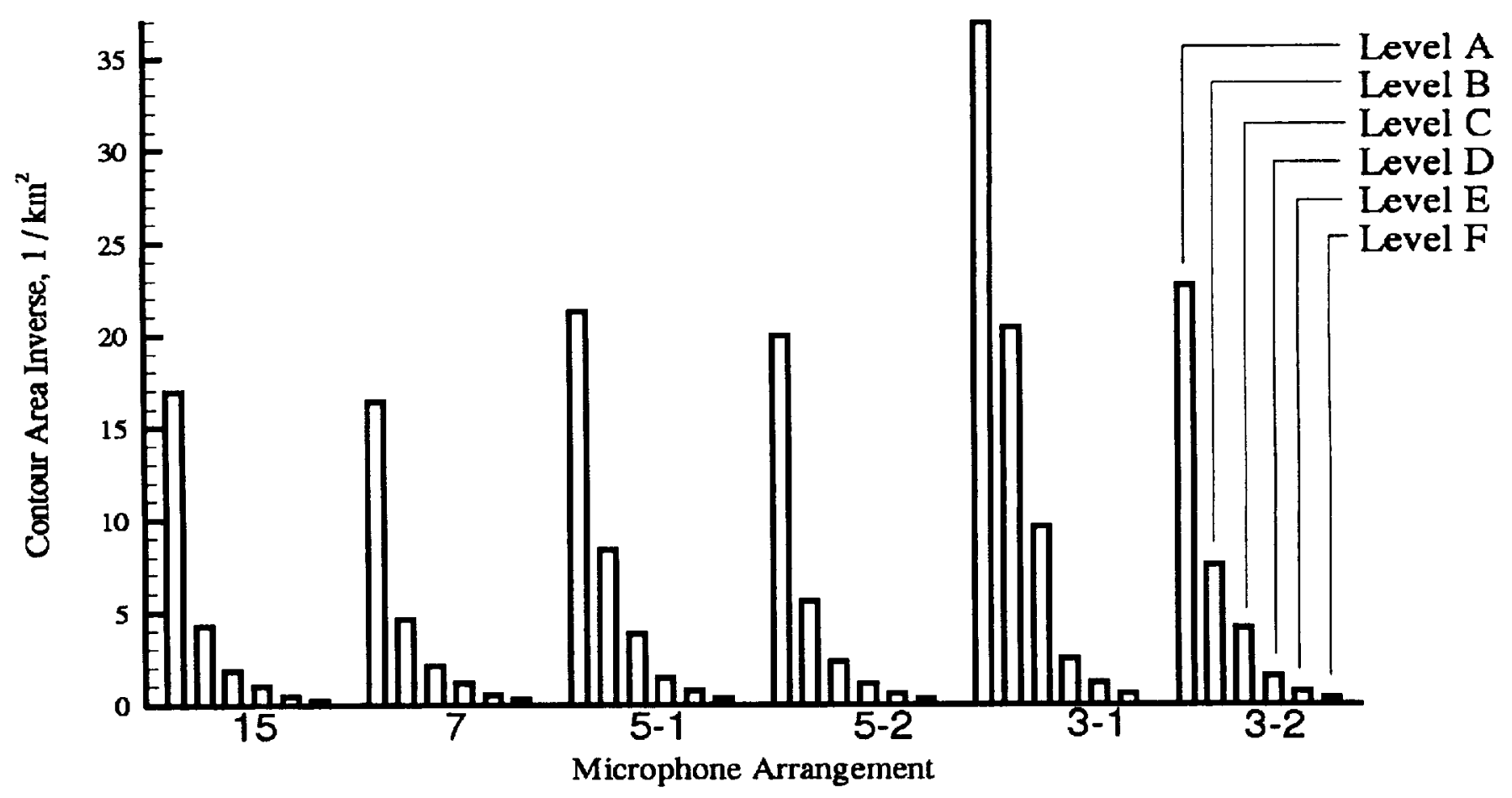

Figure 15. Contour ured vs. microphone layout for a moderate speed, $6^{\circ}$ descent flyover.

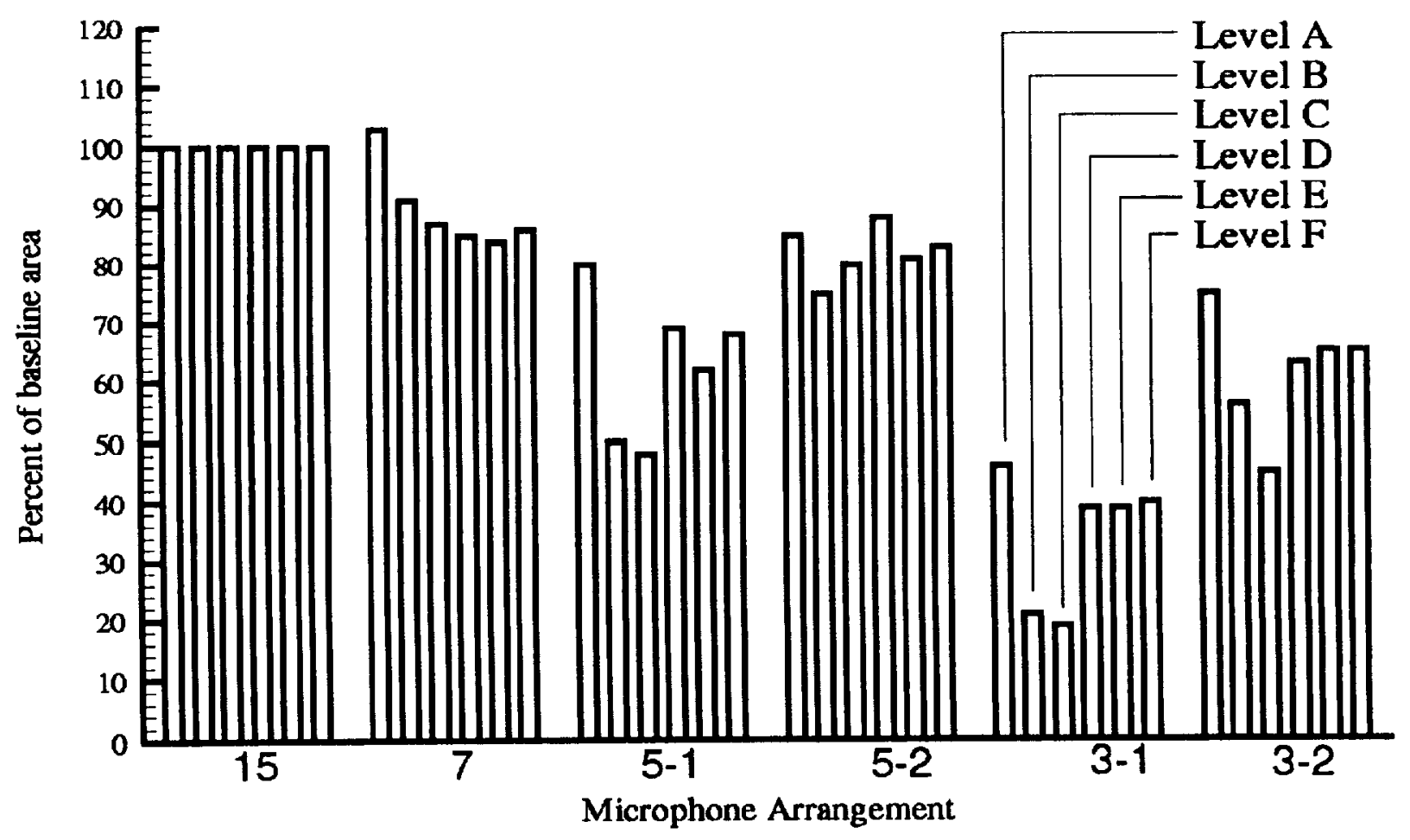

Figure 16. Percent of buseline area vs. microphone layout for a moderate speed, $6^{\circ}$ descent flyover. 


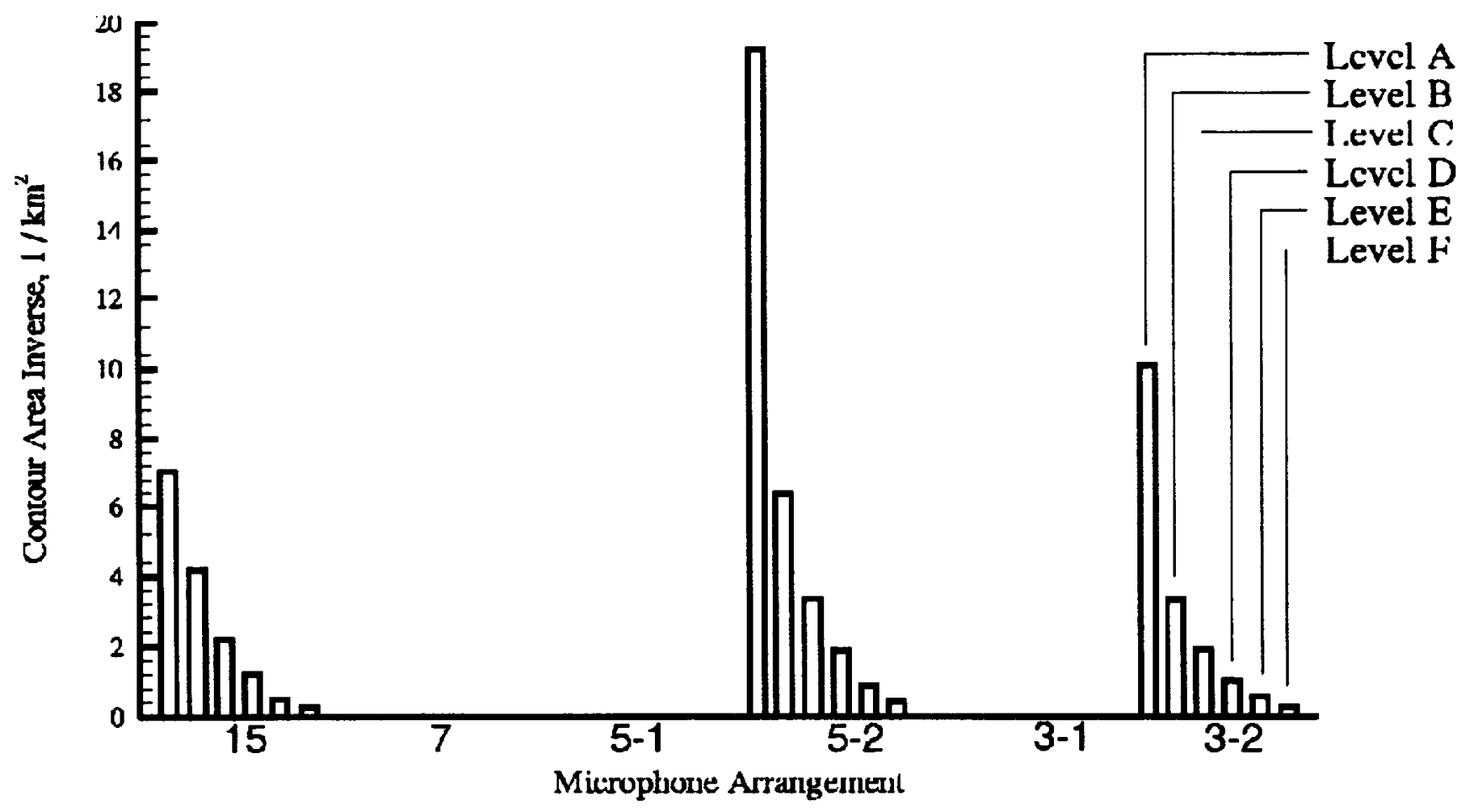

Figure 17. Contour urea vs. microphone layout for a high speed, $12^{2}$ descent flyover.

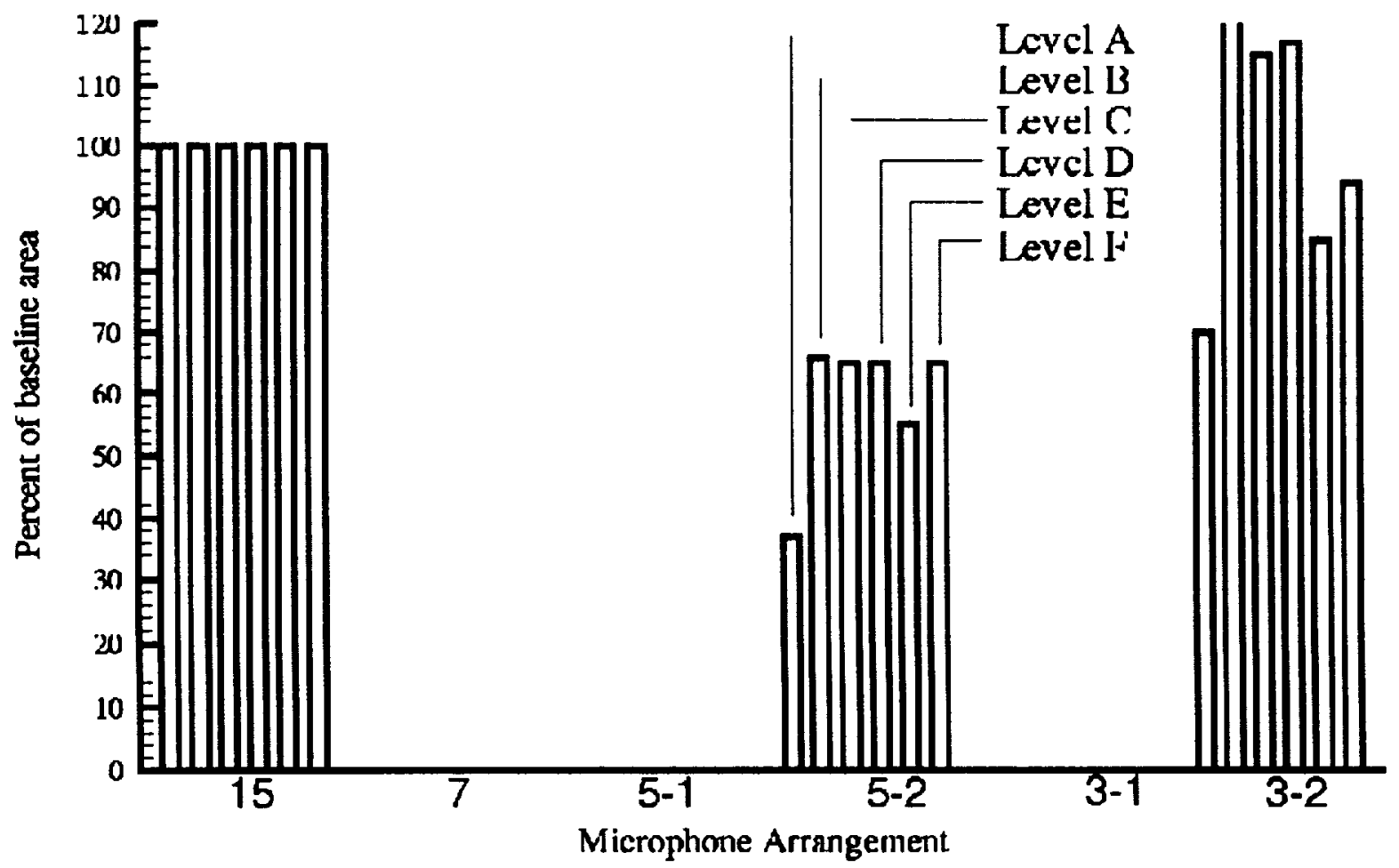

Figure 18. Percent of buseline atea vs. microphone layout for a high speed, 12" descent flyover. 